\title{
Jejunal mucosal appearances after total gastrectomy ${ }^{1}$
}

\author{
J. M. JOHNSTONE AND J. F. ADAMS \\ From the Grimsby General Hospital, Grimsby, \\ and the Western Infirmary, Glasgow
}

EDITORIAL SYNOPSIS Villous atrophy was present in two out of 14 patients after total gastrectomy, one being associated with subserosal infiltration of secondary carcinoma, but the other patient showed only minor changes in biopsies taken further from the stoma.

The examination of jejunal mucosa obtained by peroral biopsy is now accepted as a useful and important part of the investigation of patients with various malabsorptive disorders. Some form of malabsorption is common following the relatively rarely performed operation of total gastrectomy, and in the course of a long-term study of the metabolic effects of this operation jejunal biopsies were obtained and form the material for this report.

\section{MATERIAL}

Twenty-two jejunal mucosal biopsies were obtained from 14 patients, mainly by a peroral tube but occasionally at open operation, and once at necropsy, at periods up to 16 years after total gastrectomy. Details of the patients and biopsies are given in the Table. The patients were investigated over a considerable period, the majority having malabsorption in some form as shown by conventional tests of intestinal absorptive function.

After fixation in formol saline followed by formol corrosive, paraffin sections of the material were cut and stained by haemalum and eosin, trichrome stains, mucicarmine (Southgate), diazo (Pearse), van Gieson, reticulin (Gordon and Sweet), periodic-acid Schiff reagent, phosphotungstic acid haematoxylin, Gram's stain, and a modified phloxine-tartrazine stain (Lendrum).

\section{RESULTS}

Only seven biopsies were considered to be entirely normal (see Table).

In a further 13 biopsies the villi showed some broadening which, in all but one, was of minor degree and involved only a small proportion of the villi: in the one exception the villi were moderately and patchily broadened, flattened, and clubbed. The minor degree of broadening seen in at least 12 of

${ }^{1}$ Brief details of this paper were given at the Symposium on Malabsorption Syndromes at the Second World Congress of Gastroenterology, Munich, 1962. this group is of doubtful significance and may sometimes be seen in apparently normal jejunum even when taken at open operation.

Only two specimens showed gross abnormalities. In one the mucosal thickness was normal but the villi were atrophic and extremely broad, without being oedematous, giving the appearances of being pushed together and almost fused. The surface epithelium was of short columnar to cuboidal type with rounded or ovoid nuclei. Glandular hyperplasia was variable and moderate. In the subserous layer, the sample having been taken at necropsy immediately after death, there was infiltration by an anaplastic carcinoma from the stomach.

The other severely abnormal specimen was obtained from a 58-year-old man two and a half years after total gastrectomy for extensive carcinoma, the oesophagus being anastomosed to a Roux loop of jejunum. The biopsy was taken under radiological control when the tip of the biopsy tube was 3 in. $(7.5 \mathrm{~cm}$.) below the diaphragm. The total mucosal thickness was only slightly reduced but the villi were mainly short and flat, reduced in number and occasionally broad, clubbed, or oedematous (Fig. 1). The surface epithelium was sometimes vacuolated and the brush border replaced by mucinous material. The rather oedematous mucosa showed patchy glandular hyperplasia. Argentaffin cells were reduced in number and Paneth cells absent. Six weeks later a laparotomy was carried out for obscure abdominal symptoms and a mass of retroperitoneal carcinoma was found. A biopsy was taken about 8 in. $(20 \mathrm{~cm}$.) below the diaphragm and between the oesophago-jejunal and jejuno-jejunal anastomoses and showed moderate and patchy broadening, flattening, and clubbing of the villi (Fig. 2a). Another biopsy beyond the jejuno-jejunal anastomosis, and about $20 \mathrm{in}$. $(50 \mathrm{~cm}$.) below the diaphragm, was quite normal (Fig. 2b). 
TABLE I

DETAILS OF THE PATIENTS AND GRADING OF MUCOSAL APPEARANCES

\begin{tabular}{|c|c|c|c|c|c|c|c|}
\hline \multirow{3}{*}{$\begin{array}{l}\text { Case } \\
\text { No. }\end{array}$} & \multirow{3}{*}{$\begin{array}{l}\text { Age at } \\
\text { Operation } \\
\text { (yr.) }\end{array}$} & \multirow[t]{3}{*}{ Sex } & \multirow{3}{*}{$\begin{array}{l}\text { Indication for } \\
\text { Operation }\end{array}$} & \multicolumn{4}{|c|}{ Jejunal Biopsy } \\
\hline & & & & \multirow[t]{2}{*}{ Number } & \multicolumn{2}{|c|}{$\begin{array}{l}\text { Interval from } \\
\text { Operation to Biopsy }\end{array}$} & \multirow[t]{2}{*}{ Interpretation } \\
\hline & & & & & Years & Months & \\
\hline \multirow[t]{3}{*}{1} & 43 & F. & Gastric carcinoma & 1 & 5 & 8 & Minor abnormality \\
\hline & & & & $1 \mathbf{a}$ & 7 & 9 & Minor abnormality \\
\hline & & & & $1 b$ & 7 & 10 & Minor abnormality \\
\hline \multirow[t]{3}{*}{2} & 55 & M. & Gastric carcinoma & 2 & 2 & 5 & Atrophic \\
\hline & & & & $2 \mathbf{a}$ & 2 & 7 & Moderate abnormality \\
\hline & & & & $2 b$ & 2 & 7 & Normal \\
\hline 3 & 58 & M. & Gastric carcinoma & 3 & 4 & 5 & Minor abnormality \\
\hline 4 & 46 & M. & Gastric carcinoma & 4 & 1 & 5 & Minor abnormality \\
\hline 5 & 45 & M. & Peptic ulcer & 5 & 1 & 6 & Minor abnormality \\
\hline 6 & 72 & $\mathbf{M}$. & Gastric carcinoma & 6 & - & 11 & Minor abnormality \\
\hline 7 & 48 & M. & Gastric carcinoma & 7 & - & 7 & Minor abnormality \\
\hline 8 & 45 & M. & Peptic ulcer & 8 & 5 & - & Minor abnormality \\
\hline \multirow[t]{2}{*}{9} & 61 & M. & Gastric carcinoma & 9 & - & 7 & Minor abnormality \\
\hline & & & & $9 \mathbf{a}$ & - & 9 & Atrophic, carcinoma \\
\hline \multirow[t]{2}{*}{10} & 45 & M. & Gastric carcinoma & 10 & 2 & 4 & Normal \\
\hline & & & & $10 \mathbf{a}$ & 5 & - & Normal \\
\hline \multirow[t]{2}{*}{11} & 47 & M. & Corrosive gastritis & 11 & 13 & - & Normal \\
\hline & & & & $11 a$ & 16 & 8 & Normal \\
\hline \multirow[t]{2}{*}{12} & 26 & M. & Gastric angioma & 12 & - & - & Normal \\
\hline & & & & $12 a$ & 1 & 9 & Normal \\
\hline 13 & 51 & F. & Gastric ulcer & 13 & 1 & 3 & Minor abnormality \\
\hline 14 & 65 & $\mathbf{M}$ & Gastric ulcer & 14 & 1 & 6 & Minor abnormality \\
\hline
\end{tabular}

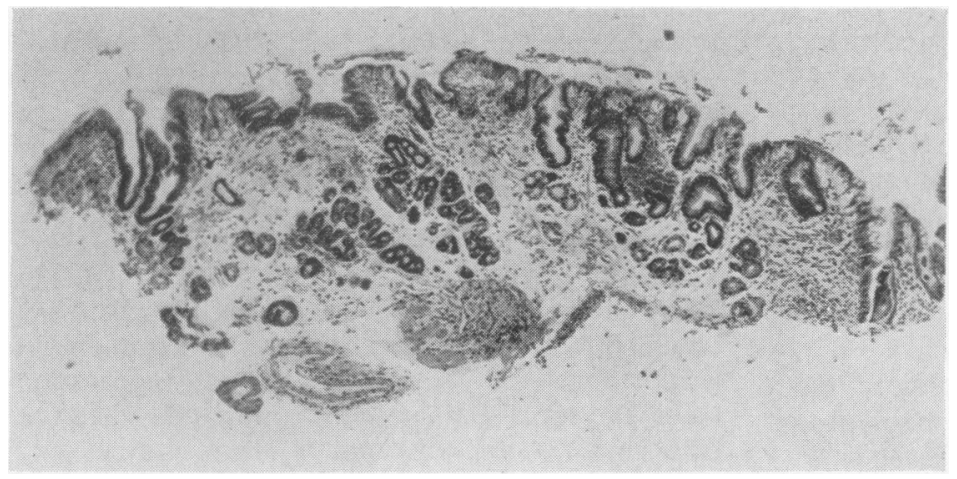

FIG. 1. Case 2. Atrophic mucosa approximately $7.5 \mathrm{~cm}$. distal to the oesophago-jejunal anastomosis. Haematoxylin and eosin. $\times 48$.

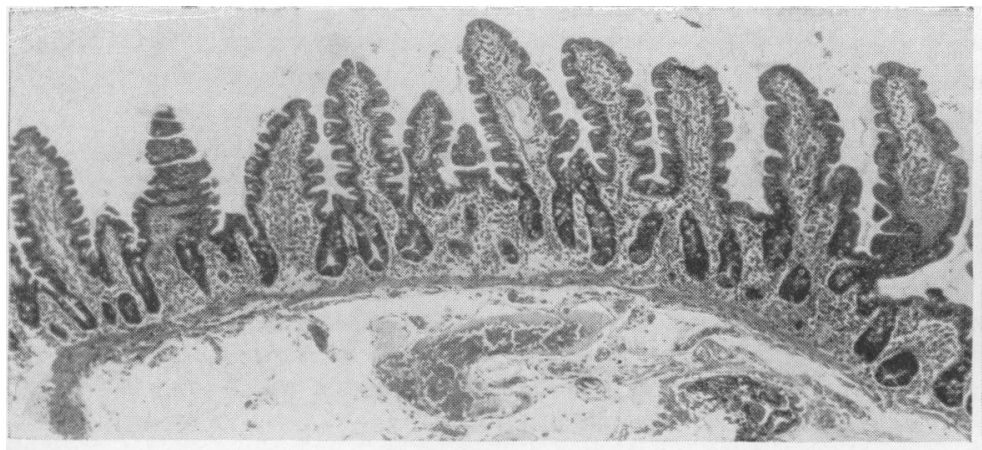

FIG. $2 \mathrm{a}$

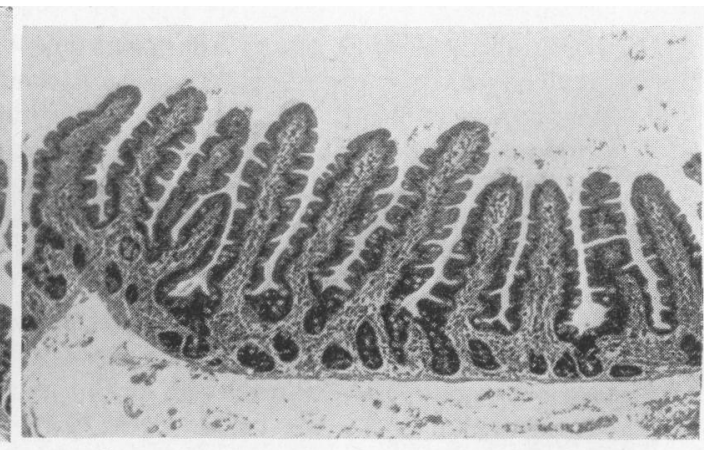

FIG. 2b

FIG. $2 \mathrm{a}$ and 2b. Case 2. Biopsies taken at approximately $20 \mathrm{~cm}$. and $50 \mathrm{~cm}$. distal to the oesophago-jejunal anastomosis two months after the biopsy in Figure 1: (a) patchy broadening of villi, (b) normal. Haematoxylin and eosin. $\times 48$. 
With the exception of the second grossly abnormal specimen mentioned above no appreciable change was noted in the numbers of polymorphs, lymphocytes or plasma cells, Paneth cells, argentaffin cells or mucous cells, in the vessels, lymphoid foci or surface mucin, or in the muscle, reticulin, or fibrous tissue. Further, there was no correlation between the mucosal changes and the age, sex, disease, type of anastomosis, nutritional state, or absorptive function of the patients.

\section{DISCUSSION}

The appearances of the jejunal mucosa following partial gastrectomy have been described by several authors. In the largest survey, that of Baird and Dodge (1957), 23 of 31 biopsy specimens were normal: the others showed mild hyperaemia, oedema, or atrophy of the villi or inflammatory infiltration of the stoma. Joske and Blackwell (1959), investigating four patients with malabsorption following partial gastrectomy, found atrophic jejunitis in three. In a similar study of post-gastrectomy steatorrhoea by Shiner (1959) material from only two of the 15 patients showed villous atrophy.

Total gastrectomy is a much less common operation and reports of jejunal mucosal appearances after this operation are consequently relatively rare. Paulson (1953) made an endoscopic study of the jejunum after total gastrectomy and described mucosal atrophy in some. His illustration of this was reproduced in a further paper the following year (Paulson and Harvey, 1954). In the present study seven biopsy specimens were normal and in a further 13 the only change was a relatively minor degree of broadening of some of the villi.

Only two specimens showed significant villous atrophy. In one (case 9) the villi were atrophic and greatly broadened in the presence of secondary carcinoma in the deeper layers of the gut wall. It seems probable, in view of the previous biopsy which showed only minor abnormalities, that the mucosal changes in this instance are secondary to the neoplastic infiltration. This association has been previously recorded by Shearman, Girdwood, Williams, and Delamore (1962) describing jejunal changes, such as are seen in primary malabsorption disease, in two patients who had steatorrhoea and malignant disease of the small bowel: one of their cases had intestinal obstruction due to a carcinoma if the jejunum while in the other the small bowel, particularly the jejunum, was infiltrated by a reticulosarcoma. In the other (case 2) the villous atrophy in the specimen taken just beyond the oesophago-jejunal anastomosis, was extremely severe. Six weeks later a subsequent biopsy taken approximately 8 in. $(20 \mathrm{~cm}$.) beyond this anastomosis showed only moderate broadening, with some clubbing and flattening of the villi in some areas, while that taken 20 in. $(50 \mathrm{~cm}$.) beyond the anastomosis was entirely normal. It is uncertain why the mucosa immediately beyond the oesophago-jejunal anastomosis should be so atrophic and yet normal some 20 in. $(50 \mathrm{~cm}$.) more distally. However it may be relevant that Anderson, Townley, Messer, and Hubbard (1962) have found mucosal changes similar to those seen in coeliac disease when the small bowel has been exposed to chronic irritants or to some abnormal condition such as ileostomy or implantation of ureters in an ileal conduit. It may be, therefore, that the abnormal circumstances produced by the oesophago-jejunal anastomosis account for the mucosal atrophy seen in this patient and possibly also for the minor changes seen in some other cases, and that the presence or absence of these changes depends simply on the distance beyond the anastomosis at which the biopsy is taken.

In any event the jejunal mucosa after total gastrectomy is, in the majority of cases, either normal or only slightly altered and any changes observed are not closely correlated with the length of interval between operation and biopsy. Further it appears that in probably all instances the malabsorption which develops after operation is not the result of mucosal changes in the upper part of the small intestine.

\section{SUMMARY}

Twenty-two specimens of jejunal mucosa have been obtained from 14 patients who had undergone total gastrectomy, the longest interval after operation being 16 years. Seven specimens were considered to be normal histologically and 13 others showed only minor abnormalities, principally broadening of some of the villi.

Villous atrophy was present in only two specimens. In one the atrophy was associated with subserosal infiltration by a secondary carcinoma. In the case of the second specimen with villous atrophy subsequent and more distal biopsies showed only minor changes or were normal.

It is suggested that the abnormal circumstances produced by the oesophago-jejunal anastomosis may account for the mucosal abnormalities and that the presence or absence of such abnormalities is determined by the distance at which the biopsy is taken from the anastomosis.

We wish to thank Professor D. F. Cappell and Dr. J. A. W. McCluskie for their helpful criticism, and the 
physicians and surgeons of the Western Infirmary, Glasgow, and the Vale of Leven Hospital, Alexandria, for allowing us to study their cases. We are also indebted to Professor D. F. Cappell for the photomicrographs.

\section{REFERENCES}

Anderson, C., Townley, R. R. W., Messer, M., and Hubbard, L. (1962). Further observations on the relationship of wheat gluten to coeliac disease. Proc. roy. Soc. Med., 55, 983-985.

Baird, I. McL., and Dodge, O. G. (1957). Jejunal biopsy after partial gastrectomy. Quart. J. Med., 26, 393-400.
Joske, R. A. and Blackwell, J. B. (1959). Alimentary histology in the malabsorption syndrome following partial gastrectomy. Lancet, 2, 379-382.

Paulson, M. (1953). Peroral jejunoscopy and duodenoscopy: endoscopy of the uppermost small intestine after total gastrectomy. Gastroenterology, 23, 593-606.

-, and Harvey, J. C. (1954). Hematological alterations after total gastrectomy. J. Amer. med. Ass., 156, 1556-1560.

Shearman, D. J. C., Girdwood, R. H., Williams, A. W., and Delamore, I. W. (1962). A study with the electron microscope of the jejunal epithelium in primary malabsorptive disease. Gut, 3, 16-25.

Shiner, M. (1959). Small intestinal biopsy: diagnostic and research value. Proc. roy. Soc. Med., 52, 10-14. 